\title{
Ripple polystyrene nano-pattern induced by KrF laser
}

\author{
P. Slepička ${ }^{1,{ }^{*},}$ O. Neděla ${ }^{1}, J$. Siegel ${ }^{1}$, R. Krajcar ${ }^{1}$, Z. Kolská ${ }^{2}$, V. Švorčík ${ }^{1}$ \\ ${ }^{1}$ Department of Solid State Engineering, Institute of Chemical Technology, 16628 Prague, Czech Republic \\ ${ }^{2}$ Faculty of Science, J.E. Purkyně University, Ústí nad Labem, Czech Republic
}

\begin{abstract}
The study of excimer laser treatment of polystyrene surface was performed. The influence of laser fluence and number of laser pulses on surface chemistry and morphology was determined. The surface morphology and roughness were studied with atomic force microscopy. Surface wettability and aging studies were characterized by the water contact angle measurements. Surface oxygen concentration and chemistry were evaluated from X-ray photoelectron spectroscopy and zeta potential measurements. The optimal polystyrene treatment parameters for the most regular pattern were determined. The foils with optimal ripple pattern were subsequently sputtered with gold nano-layers of $100 \mathrm{~nm}$ thickness. It was found that the surface roughness of PS strongly depends on number of pulses. The aging study revealed that the higher contact angle achieve the samples treated with higher laser fluence. The deposition of gold nano-layer increases the surface roughness of nano-patterned surface. It was proved that the oxygen concentration is significantly influenced by the KrF laser exposure.
\end{abstract}

Keywords: nanomaterials, excimer laser, ripple pattern, polymer, metal coating

\section{Introduction}

Excimer laser treatment has been recently used for production of LIPPS nanostructures on PS, PET, PI or semiconductor surfaces [1-3]. Different methods (ArF excimer laser irradiation and radio-frequency (RF) plasma treatment) were applied in separate procedures to create a vast range of physicochemical characteristics on the surface of polystyrene (PS) and investigate their effects on blood compatibility of treated surfaces [1]. The changes in surface topography and chemistry were analyzed by atomic force microscopy (AFM). Recently, one-dimensional metal nanostructures with high aspect ratio have drawn remarkable attention owing to their anisotropic electrical and optical properties that differ from those observed in the bulk materials. These properties offer interesting applications in various areas e.g. in electronic devices [4] or surface-enhanced Raman scattering (SERS) [5]. The detailed description of polystyrene ageing process, its morphologi- cal study and interaction with metal nanolayers after excimer laser treatment remained still unclear. Electrical conductivity of organic polymers can be permanently changed by the series of excimer laser pulses [1-5]. Therefore the polymers can be transformed in situ into an electrical conductors with sufficient space resolution (micrometer and lower). Advantages of conductivity change induced by excimer laser are its simplicity and easy adaptability to excimer laser equipment [6]. Factor which is limiting for potential applications of laser exposed polymers is the spatial resolution. By direct ablation of polyimide by $\mathrm{KrF}$ excimer laser it is possible to prepare lines with the width of less than $100 \mathrm{~nm}$ [7]. Such structures can be used in micro-electronics, e.g. for construction of semiconductor lasers in visible light area [8]. Metallization of polymer surface is important for several applications, involving microelectronic integrated circuits or bio-compatible carriers for medical applications. Adhesion at the metal/

\footnotetext{
*Corresponding author, e-mail: petr.slepicka@vscht.cz

(C) BME-PT
} 
polymer interface is influenced by the structure and chemical properties of material and can be, therefore, influenced by heat treatment, chemical etching or exposure of polymer to inert or reactive plasma before the metallization itself [9]. Also other methods for ripple nanopatterning have been proposed recently, which are based on the combination of plasma treatment, metallization and subsequent heating [10-12].

Polystyrene is a thermoplastic polymer widely used in many technological fields, such as micro-electronics, LOC (lab-on-chip) devices, membranes and scaffolds for cell cultivation [13]. The important PS properties are hardness, stiffness, easiness in thermal manufacturing and excellent thermal and electrical properties, they are easily applicable as insulators [14]. Functional properties are affected by low surface energy, hydrophobicity and low reactivity of this polymer. For suppression of last mentioned properties, and therefore improvement of adhesive potential of such substrate it is possible to use multiple approaches, such are e.g. plasma treatment or exposure by UV-lamp, so that the surface layer could be altered [15]. Increase of surface energy induced by these methods influences not only the adhesion, but also its tribological properties [16]. Laser beam allows performing precise changes of only small fragments or thickness of surface layer [17]. UV light can also induce several chemical reactions, which may alter the amount of surface polar groups on the surface $[18,19]$. Nanosecond pulses of UVbeam of high energy lead to creation of significantly higher amount of radicals on the surface. Due to time dependence of diffusion processes in gas phase and surface layer cannot be the radicals fully saturated by reaction with air oxygen, therefore the recombination processes take place [15]. Physico-chemical processes connected with changes induced by laser beam are not still yet fully understood and are subject of continual intensive research [20]. Considerable attention has been devoted to laser assisted patterning and treatment of PS in connection with its application in research field of cell cultivation [21]. Changes of surface properties induced in the PS layer by ArF excimer laser were recently presented [22]. PET foils have been also treated with excimer lasers and the ripple pattern has been constructed [23, 24].

Papers regarding the nano-pattern formation on PS have been already published $[21,22,25,26]$. Also their applications in cell biocompatibility were proposed $[15,21,27]$. The main motivation and novelty of the work is the detail study of PS wettability and ageing, morphology and zeta-potential changes induced by $\mathrm{KrF}$ laser, which are presented in this paper in detail. Also the growth of the consequently sputtered metal layers is described. The changes in the surface morphology were studied with atomic force microscopy (AFM), chemical structure was analyzed with X-ray induced photo-electron spectroscopy (ARXPS) and zeta potential measurement. Consequent metallization with gold nanolayer on selected pattern was performed and studied with AFM.

\section{Materials and methods}

Oriented PS foils with a thickness of $50 \mu \mathrm{m}\left(T_{\mathrm{m}} \sim\right.$ $240^{\circ} \mathrm{C}, T_{\mathrm{g}} \sim 100^{\circ} \mathrm{C}$, supplied by Goodfellow Ltd., UK) were used.

The PS samples were treated with a $\mathrm{KrF}$ laser (Lambda Physik Compex Pro 50, wavelength of $248 \mathrm{~nm}$, repetition rate $10 \mathrm{~Hz}$ ). For the sake of homogeneity only central part of the beam profile, defined by an aperture $5 \times 10 \mathrm{~mm}$, was used for the irradiation. The samples were mounted onto a translation stage and scanned perpendicularly to the sample surface normal under ambient atmosphere (irradiation in air). The laser fluence used in present experiment was in interval $6-14 \mathrm{~mJ} \cdot \mathrm{cm}^{-2}$, number of pulses varied from 200 to 8000, applied frequency was $10 \mathrm{~Hz}$. The optical table Performance 07OTM501 (Melles Griot) with air pressured outriggers was used. For the polarization the cube of UV grade fused silica $25 \times 25 \times 25 \mathrm{~mm}^{3}$ with active polarization layer was used. Optical path was constructed from dielectric mirrors from $\mathrm{SiO}_{2}$ for reflectance $248 / 633 \mathrm{~nm}$. The stage with the samples was directed by Laser XY software, the motorized shift NRT100/M2 (Melles Griot).

The gold layers on pristine and laser treated PS (original dimensions of non-treated sample $2 \times 2 \mathrm{~cm}^{2}$, the treated area $0.5 \times 1 \mathrm{~cm}^{2}$ ) were deposited from a gold target $(99.999 \%)$ by means of diode sputtering technique (BAL-TEC SCD 050 equipment). Typical sputtering conditions were: room temperature, time $300 \mathrm{~s}$, total argon pressure of about $5 \mathrm{~Pa}$, electrode distance of $50 \mathrm{~mm}$ and current $40 \mathrm{~mA}$. For the layer thickness measurement the gold was deposited under the same conditions on a $\mathrm{Si}(100)$ substrate. The gold layer thickness was determined from scratches (steel 
needle) measured with AFM. Typically five measurements on three scratches each were accomplished on each sample. The thickness of the gold layer sputtered under above described conditions was $100 \pm 10 \mathrm{~nm}$.

The surface morphology was examined using the AFM. The AFM images were taken under ambient conditions on a Digital Instruments CP II set-up. The samples were mounted on a sample holders using double-sided adhesive tape. The 'tapping mode' was chosen for the measurements to minimize damage to the samples surfaces. A Veeco oxide-sharpened P-doped silicon probe RTESPA-CP attached to a flexible micro-cantilever was used near its resonant frequency of $300 \mathrm{kHz}$. The scans were acquired at ambient atmosphere at a line scanning rate of $1 \mathrm{~Hz}$. All surfaces were characterized both quantitatively by measuring the mean roughness $\left(R_{\mathrm{a}}, 10 \times 10 \mu \mathrm{m}^{2}\right)$ and morphology. $R_{\mathrm{a}}$ represents the arithmetic average of the deviations from the center plane of the sample. Four areas of each sample were scanned in order to obtain representative data.

Water contact angle (CA) characterizing surface wettability was determined by goniometry. The measurements of the CA were performed using distilled water on 4 different positions (i.e. 4 droplets, droplet volume $8 \mu \mathrm{L}$ ). The water drops were applied on surface of the substrate, photographed and evaluated by three-point method using the Surface Energy Evaluation System (Advex Instruments, CR). The error of contact angle measurements did not exceed $\pm 5^{\circ}$. An Omicron Nanotechnology ESCAProbeP spectrometer was used to measure ARXPS spectra. The $2 \times 3 \mathrm{~mm}^{2}$ area was analyzed. The X-ray source provided monochromatic radiation of $1486.7 \mathrm{eV}$. The spectra were measured stepwise with a step in the binding energy of $0.05 \mathrm{eV}$ at each of the six different sample positions with respect to the detector axis, which translated into different angles $(0,67$ and $81^{\circ}$ ). The spectra evaluation was carried out by using CasaXPS software. The concentrations of the elements were given in at $\%$.

Zeta potential measurements of all samples were accomplished on SurPASS Instrument (Anton Paar $\mathrm{GmbH}$, Austria) by a streaming current method and Helmholtz-Smoluchowski equation for zeta potential calculation was employed. Samples were studied inside the adjustable gap cell with an electrolyte of $0.001 \mathrm{~mol} \cdot \mathrm{dm}^{-3} \mathrm{KCl}$ at constant $\mathrm{pH}=6.1$. Two samples of each surface were measured four times with the relative error of $10 \%$. Zeta potential was measured on pristine sample, and on sample treated by laser: (i) in parallel and (ii) perpendicularly to the ripple pattern to study an effect of surface roughness to surface chemistry, surface charge and zeta potential.

\section{Results and discussion}

\subsection{Pattern properties and morphology}

The first goal of our study was to determine the influence of different laser energies onto surface morphology when a constant number of pulses is applied. Polystyrene foils were exposed to the laser beam with fluences $6-12 \mathrm{~mJ} \cdot \mathrm{cm}^{-2}$ using 6000 pulses (Figure 1). We determined that with increasing laser fluence a mild increase of surface roughness occurred (fluences below $10 \mathrm{~mJ} \cdot \mathrm{cm}^{-2}$ ) (Figure 2). The consequent increase of laser fluence to up to $12 \mathrm{~mJ} \cdot \mathrm{cm}^{-2}$ is connected with rapid increase of the surface roughness. The second goal was to determine the laser fluence from which the ripple pattern appears. For treated PS the value was determined to be $8 \mathrm{~mJ} \cdot \mathrm{cm}^{-2}$. If the applied laser fluence is between 9 and $10 \mathrm{~mJ} \cdot \mathrm{cm}^{-2}$ the fully developed ripple pattern accomplished with significant roughness increase appears. Consequent increasing of laser fluence leads to slow diminishing of ripple nano-pattern. The nanopattern diminishing is connected with the roughness decrease, since the Z-values of pattern decrease (see Figure 2). The dimensions of fully developed ripples were determined as follows: for laser fluence $9 \mathrm{~mJ} \cdot \mathrm{cm}^{-2}$ the height of the structures was $(38.6 \pm 4.0) \mathrm{nm}$ and the width was $(250.0 \pm 12.3) \mathrm{nm}$, for fluence $10 \mathrm{~mJ} \cdot \mathrm{cm}^{-2}$ the observed ripple height
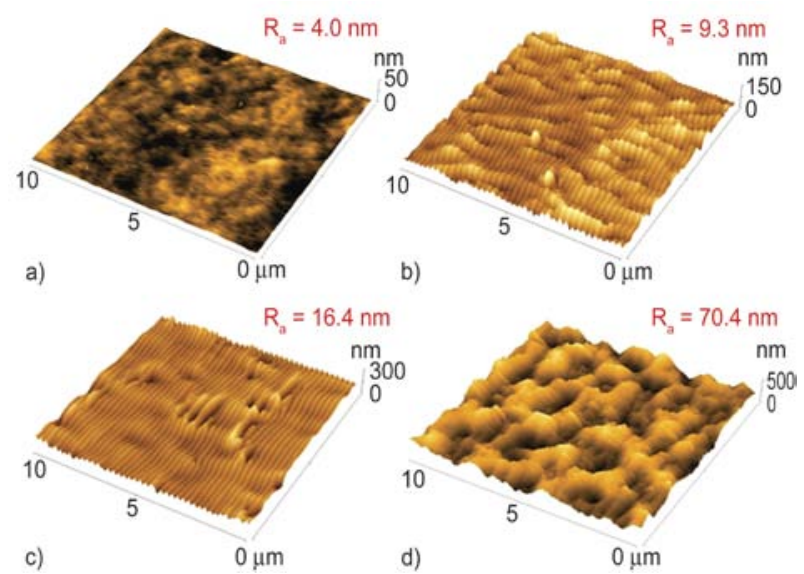

Figure 1. The surface morphology of PS exposed with laser fluence with 6 (a), 8 (b), 10 (c) and $12 \mathrm{~mJ} \cdot \mathrm{cm}^{-2}$ (d) for number of pulses 6000 . The $R_{\mathrm{a}}$ represents the average surface roughness in $\mathrm{nm}$. 


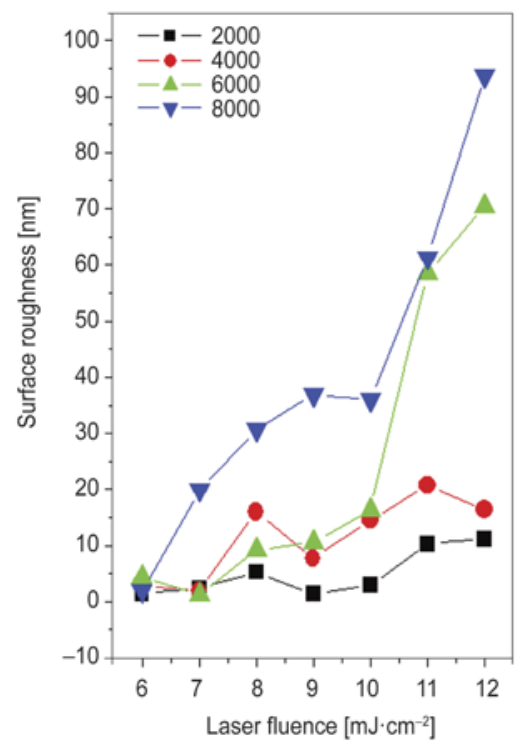

Figure 2. Dependence of PS surface roughness $R_{\mathrm{a}}$ $\left(10 \times 10 \mu \mathrm{m}^{2}\right)$ on laser fluence for number pulses $2000-8000$

was $(24.8 \pm 0.7) \mathrm{nm}$ and ripple width $(247.8 \pm 7.8) \mathrm{nm}$. The results of pattern depth are with excellent agreement with those obtained [21]. The width periodicity is slightly higher, may be due to higher thickness of applied polymer foil ( 25 vs. $50 \mu \mathrm{m}$ [21]). The thickness of polymer foil may influence the thermal flux, which can further lead to the slightly different results in comparison to [21].

Consequently, the whole experiment was repeated in the range of laser fluence $6-12 \mathrm{~mJ} \cdot \mathrm{cm}^{-2}$ for 2000 , 4000 and 8000 pulses (Figure 2). It was found, that for 2000 and 4000 pulses the mild roughness increase occurs. A rapid increase of surface roughness with increasing laser fluence was observed at 8000 pulses. If the laser fluence $6 \mathrm{~mJ} \cdot \mathrm{cm}^{-2}$ is applied the $R_{\mathrm{a}}$ does not change with the increasing number of pulses significantly, while for laser fluence $12 \mathrm{~mJ} \cdot \mathrm{cm}^{-2}$ a rapid increase of $R_{\mathrm{a}}$ is observed for 6000 pulses and above (Figure 2). It appears that if the higher laser fluence is applied $\left(9-12 \mathrm{~mJ} \cdot \mathrm{cm}^{-2}\right.$, in combination with lower number of laser pulses), the homogeneous ripple pattern is also constructed on the PS surface (Figure 3). As expected, the number of pulses and laser fluence have a strong effect on ripple pattern formation [23, 24], the combination of high laser fluence and low number of laser pulses can lead to the homogeneous ripple nanopattern on PS, which as a consequence lead to the surface roughness increase (Figure 2 and Figure 3c).

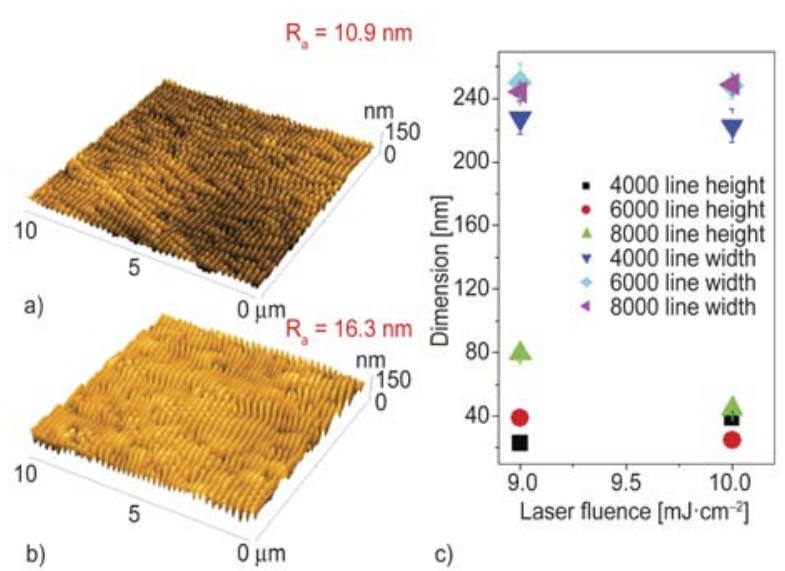

Figure 3. The surface morphology of PS treated with $12 \mathrm{~mJ} \cdot \mathrm{cm}^{-2}$ and number of pulses 2000 (a) and 4000 (b). The dependence of the width and height of PS prepared structure on the laser fluence and by number of pulses 4000, 6000 and 8000 is introduced in (c).

\subsection{Surface wettability and aging}

The consequent metallization or cell adhesion and proliferation can be significantly enhanced or suppressed by the wettability (surface polarity) of the modified surface. Therefore we studied the surface contact angle of selected samples treated with laser fluence 6,9 , and $12 \mathrm{~mJ} \cdot \mathrm{cm}^{-2}$ with laser pulses in the interval 200-6000 immediately after the exposure. It was observed, that with increasing number of laser pulses as a consequence the contact angle decreases (Figure 4a) in comparison to pristine PS, which confirms the increase of wettability after laser exposure and it is also with an agreement with work [21]. The contact angle decreases with the number of pulses up to certain value. After that a saturation value is reached and the contact angle is slightly increased with the number of pulses for some fluence (laser fluence $12 \mathrm{~mJ} \cdot \mathrm{cm}^{-2}$ ). The hydrophilicity is increased due to formation of surface radicals after polymer bonds breakage caused by the impact and absorption of laser beam and consequent creation of new oxygen (polar) groups [28]. The application of laser fluence $12 \mathrm{~mJ} \cdot \mathrm{cm}^{-2}$ leads to the minimum of contact angle for 3000 pulses, after which the slight increase of contact angle is observed again. The same trend was observed for laser fluence $9 \mathrm{~mJ} \cdot \mathrm{cm}^{-2}$ and 5000 pulses. Also the possible ablation effects may have an influence of the amount of oxygen groups on the modified surface [28]. 

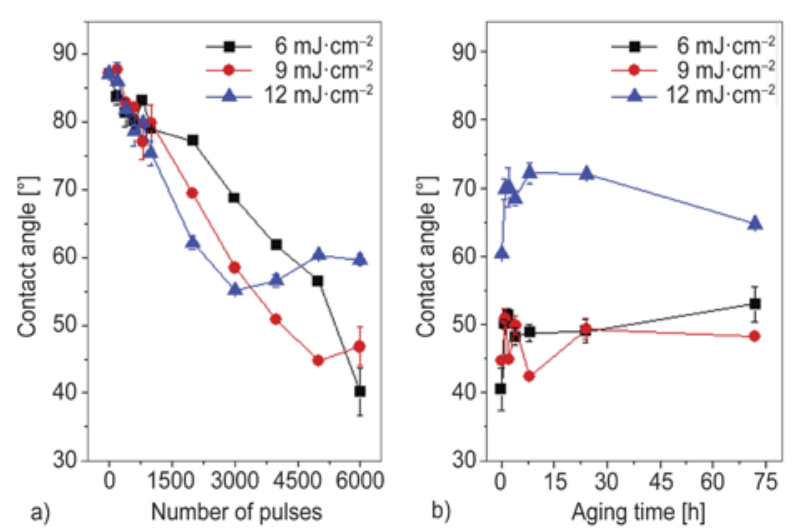

Figure 4. Dependence of contact angle of laser treated PS on number of laser pulses treated with fluences 6$12 \mathrm{~mJ} \cdot \mathrm{cm}^{-2}$ (a). The graph (b) represents dependence of contact angle on time from the laser treatment (aging time) for samples exposured with 6000 pulses and laser fluence 6,9 and $12 \mathrm{~mJ} \cdot \mathrm{cm}^{-2}$

Consequently the samples were treated with $6-$ $12 \mathrm{~mJ} \cdot \mathrm{cm}^{-2}$ and 6000 pulses at ambient atmosphere, and the ageing procedure was followed in the interval 1-72 hours (Figure 4b). If the laser fluence $6 \mathrm{~mJ} \cdot \mathrm{cm}^{-2}$ was applied, the mild increase of contact angle up to $50^{\circ}$ was observed. The treatment with fluence $9 \mathrm{~mJ} \cdot \mathrm{cm}^{-2}$ induced the fluctuation in contact angle during the early stages of aging. After 24 hours of consequent aging the mild constant decrease was determined. A different situation was observed if the fluence $12 \mathrm{~mJ} \cdot \mathrm{cm}^{-2}$ was applied. At this laser fluence firstly a sharp increase up to $70^{\circ}$ was observed, after achieving its maximum the following slow decrease was detected. After 72 hours the polymer surfaces can be signed as 'aged', i.e. with no further significant changes. The phenomenon of aging is connected with the amount of oxygenated groups and radicals on the modified surface and more importantly with the amount of oxygenated groups which rotated during the aging process into the polymer bulk. Also the ablation of surface modified layer may influence the different surface contact angle and its changes during the aging process. The knowledge of the aging process is of great importance, since together with the surface chemistry and morphology play an important role in biocompatibility applications [21].

\subsection{Surface chemistry}

The surface chemistry was evaluated by the surface oxygen concentration determined with ARXPS. The samples treated with $6-12 \mathrm{~mJ} \cdot \mathrm{cm}^{-2}$ with 6000 pulses were determined (Figure 5). It was confirmed ear-

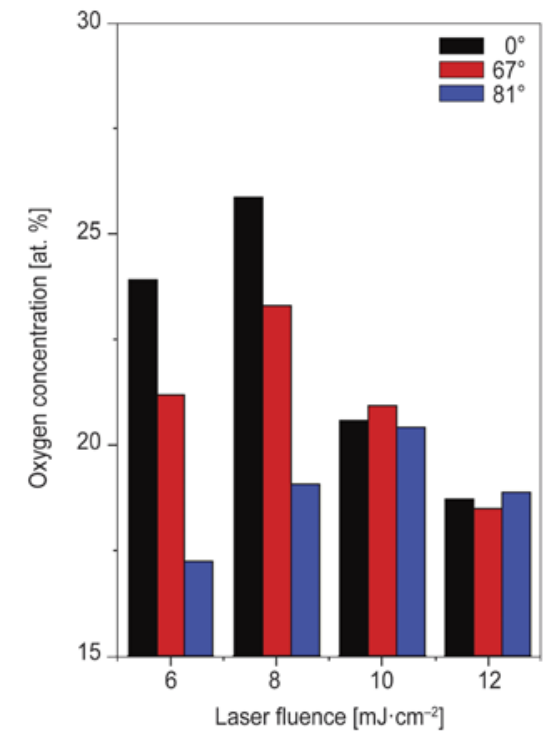

Figure 5. The dependence of oxygen concentration for treated PS on laser fluence (6000 pulses). The detection angles of photoelectrons by ARXPS were 0,67 and $81^{\circ}$.

lier, that excimer laser exposure may lead to a significant changes in in surface chemistry of biopolymer $[12,28]$. It was found, that maximum oxygen concentration was detected under perpendicular position of the sample to the detector (i.e. $0^{\circ}$ ), which means, that the data are observed mostly from the whole plane of the sample. By changing the detection angle also a penetration depth of photoelectrons changes. With increasing angle of photoelectrons detection the oxygen concentration mostly decreased. Also the difference between the particular oxygen concentrations collected for the different detection angles decreases with the increasing laser fluence. The oxygen concentration and its distribution can have a significant influence on the consequent growth of the metal structures and may also influence cell growth and proliferation positively [21].

Zeta potential diagram can describe the surface charge and surface chemistry as a function of surface morphology due to inhomogeneity of created electrical double layer when the surface is rough. The zeta-potential determination is closely related to the oxygen concentration, wettability and ability to catch and release ions, which may have a significant influence on consequent biocompatibility applications and potentially can also influence the metal layer growth. The influence of ripple pattern on zeta potential determined by streaming current method is introduced in Figure 6. Apparently the 


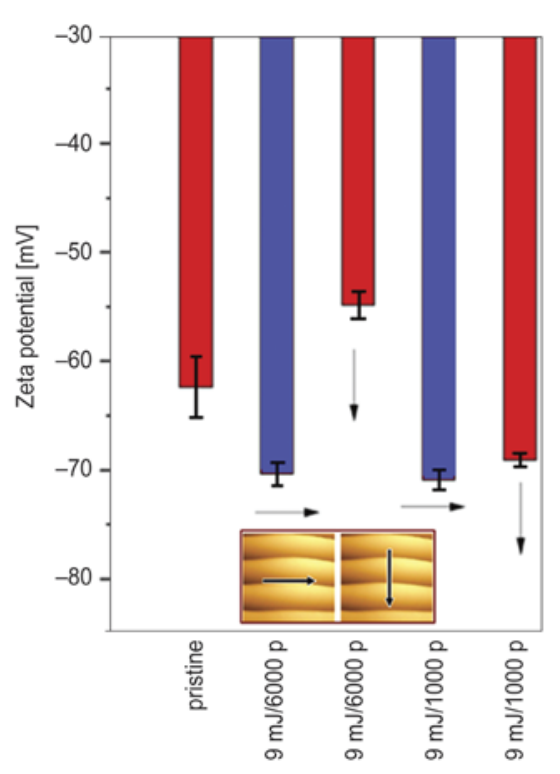

Figure 6. Zeta potential of pristine PS, PS treated with $9 \mathrm{~mJ} \cdot \mathrm{cm}^{-2}$ and 6000 resp. 1000 pulses with perpendicular flow (to the ripple pattern) in the chamber $(\uparrow)$ and parallel flow $(\rightarrow)$ of the electrolyte

zeta potential depends strongly on surface roughness and morphology that means on the electrolyte flow through the surface in parallel or perpendicular position to the surface ripple pattern. It is evident, that the zeta potential values of PS treated with $9 \mathrm{~mJ} \cdot \mathrm{cm}^{-2}$ (both 1000 and 6000 pulses) are almost similar, if the direction of the electrolyte flow applied on the PS surface is in parallel with the surface pattern structure. Rather different situation is observed, when the electrolyte is applied perpendicularly to the ripple pattern. The big difference of zeta potential evolution was achieved for 6000 pulses, when the difference in zeta potential was over $15 \mathrm{mV}$. The influence of ripple pattern on the ability of ion capturing and release was confirmed, since the PS surface treated with only 1000 pulses exhibited significantly lower difference if compared the perpendicular and parallel electrolyte flow. These differences can be caused by the amount of oxygen groups on surface. While the electrolyte flows parallel to the ripples, majority of oxygen groups created during laser treatment on surface (either on the 'hills' or in the 'valleys' of the surface) is in contact with electrolyte and electrical double layer is created homogenously on the whole surface. If the electrolyte flows perpendicularly to the ripples, the situation is different, due to the higher surface roughness electrical double layer is created only on the 'hills'. As it was proved previously, amount of oxygen groups created by laser treatment on the surface is different on the 'hills' and in the 'valleys' significantly [29].

\subsection{Gold nanolayers deposition}

The polystyrene exposed with laser fluence 6$12 \mathrm{~mJ} \cdot \mathrm{cm}^{-2}$ and 6000 pulses was consequently metallized with $100 \mathrm{~nm}$ of Au layer so that the influence of input surface morphology and chemistry on consequent metallization could be studied. The gold sputtering increases the surface roughness in the interval of laser fluences $6-10 \mathrm{~mJ} \cdot \mathrm{cm}^{-2}$ significantly, however on samples with no regular structure the sputtering has no such dramatic effect (Figure 7). The effect of roughness change is opposite to those obtained on PEN [30]. This difference is probably caused by the lower homogeneity of ripple pattern, which together with differences in surface chemistry can cause different gold nanocluster formation on the PS surface. However, the ripple pattern structure created in interval $8-10 \mathrm{~mJ} \cdot \mathrm{cm}^{-2}$ is maintained also after gold sputtering process (Figure 8). For lower laser fluences the globular structure is preserved after Au metallization. On the contrary, the gold metallization does not have any significant influence on the surface roughness or pattern formation for higher laser fluences $11-12 \mathrm{~mJ} \cdot \mathrm{cm}^{-2}$ (Figure 8c), because of higher ripple pattern roughness. It was also observed, that the width of the ripple pattern remains similar to that without metallization. The pattern of Au deposited foils was proved to be electrically continuous. The height of the ripple pattern increases or remains similar after Au metallization.
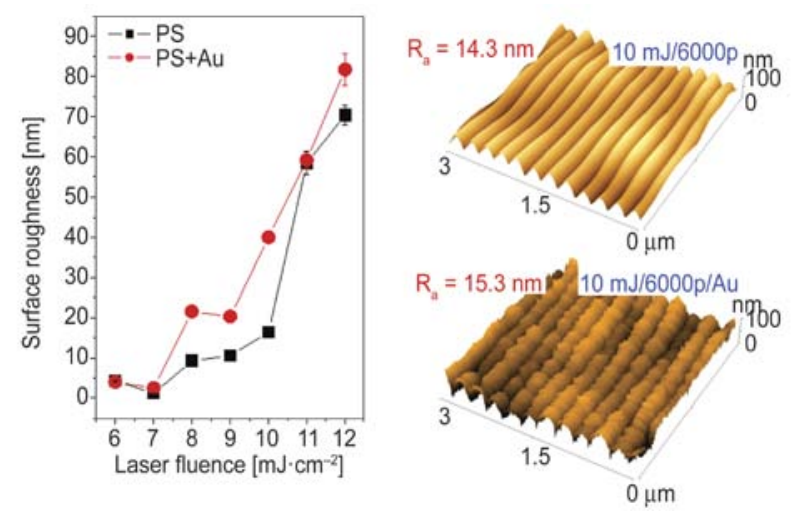

Figure 7. Dependence of PS surface roughness $\left(10 \times 10 \mu \mathrm{m}^{2}\right)$ on laser fluence in the interval $6-12 \mathrm{~mJ} \cdot \mathrm{cm}^{-2}$ (treated by 6000 pulses) and the same set of samples consequently metallized with $100 \mathrm{~nm}$ of $\mathrm{Au}$. The AFM detail structure of laser treated PS $\left(10 \mathrm{~mJ} \cdot \mathrm{cm}^{-2}\right.$ and 6000 pulses $)$ and the same sample metallized with $100 \mathrm{~nm}$ of $\mathrm{Au}$ is also introduced. 


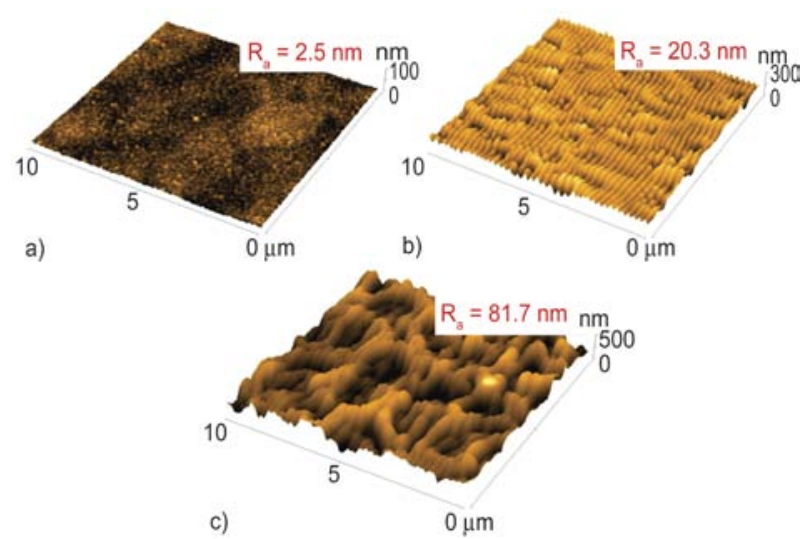

Figure 8. The surface morphology of PS laser treated (6000 pulses) by 7 (a), 9 (b) and $12 \mathrm{~mJ} \cdot \mathrm{cm}^{-2}$ (c) and consequently metallized with $100 \mathrm{~nm}$ of $\mathrm{Au}$. The $R_{\mathrm{a}}$ represents the average surface roughness in nm.

\section{Conclusions}

A study of $\mathrm{KrF}$ laser treatment on PS foil surface was performed. The influence of number of laser pulses and laser fluence on surface properties (morphology, wettability and chemistry) of PS was investigated. The optimal input parameters for ripple nano-patterning with high regularity were determined. The input parameters for construction of ripple-like surface with extremely high roughness were determined. It was found that the surface roughness of PS is strongly dependent on number of pulses. The surface chemistry of exposed PS was studied with ARXPS and zeta potential measurements. It was proved, that the oxygen concentration is significantly influenced by the $\mathrm{KrF}$ laser exposure. The wettability strongly increases with number of pulses in comparison to the pristine PS. The aging study revealed that the higher contact angle achieves the samples treated with higher laser fluence. The PS ripple nano-pattern has a strong influence on the zeta potential of studied surface, i.e. it has the capability to influence the electrolyte flow (parallel vs. perpendicular position). The deposition of gold nano-layer increases the surface roughness of nano-patterned surface. As previously confirmed the applications of nano-patterned PS surface are promising as tissue carriers, metallized pattern can find application in construction of SERS.

\section{Acknowledgements}

This work was supported by the Grant Agency of the CR under the project No. 13-06609S.

\section{References}

[1] Bagheri-Khoulenjani S., Mirzadeh H.: Polystyrene surface modification using excimer laser and radiofrequency plasma: Blood compatibility evaluations. Progress in Biomaterials, 1, 4/1-4/8 (2012).

DOI: $10.1186 / 2194-0517-1-4$

[2] Sanz M., Rebollar E., Ganeev R. A., Castillejo M.: Nanosecond laser-induced periodic surface structures on wide band-gap semiconductors. Applied Surface Science 278, 325-329 (2013). DOI: 10.1016/j.apsusc.2012.11.137

[3] Zheng H. Y., Tan T. T., Zhou W.: Studies of KrF laserinduced long periodic structures on polyimide. Optics and Lasers in Engineering, 47, 180-185 (2009).

DOI: $10.1016 /$ j.optlaseng.2008.06.015

[4] Xu F., Zhu Y.: Highly conductive and stretchable silver nanowire conductors. Advanced Materials, 24, 51175122 (2012). DOI: 10.1002/adma.201201886

[5] Liu S., Chen N., Li L., Pang F., Chen Z., Wang T.: Fabrication of $\mathrm{Ag} / \mathrm{Au}$ core-shell nanowire as a SERS substrate. Optical Materials, 35, 690-692 (2013). DOI: $10.1016 /$ j.optmat.2012.10.033

[6] Phillips H. M., Smayling M. C., Sauerbrey R.: Modification of electrical conductivity and surface structure in polymers using ultraviolet laser radiation. Microelectronic Engineering, 20, 73-88 (1993). DOI: $10.1016 / 0167-9317(93) 90208-\mathrm{M}$

[7] Phillips H. M., Callahan D. L., Sauerbrey R., Szabó G., Bor Z.: Sub-100 nm lines produced by direct laser ablation in polyimide. Applied Physics Letters, 58, 2761-2763 (1991).

DOI: $10.1063 / 1.104778$

[8] Korn M., Körfer T., Forchel A., Roentgen P.: First order distributed feedback gratings $(92.5-105 \mathrm{~nm}$ period) for GaInP/AlGaInP lasers emitting in the visible range. Journal of Vacuum Science and Technology B, 8, 1404-1407 (1990).

DOI: $10.1116 / 1.585086$

[9] Le Q. T., Pireaux J. J., Verbist J. J.: Surface modification of PET films with RF plasma and adhesion of in situ evaporated Al on PET. Surface and Interface Analysis, 22, 224-229 (2004). DOI: $10.1002 /$ sia. 740220150

[10] Slepička P., Trostová S., Slepičková Kasálková N., Kolská Z., Sajdl P., Švorčík V.: Surface modification of biopolymers by argon plasma and thermal treatment. Plasma Processes and Polymers, 9, 197-206 (2012). DOI: $10.1002 /$ ppap.201100126

[11] Slepička P., Fidler T., Vasina A., Švorčík V.: Ripplelike structure on PLLA induced by gold deposition and thermal treatment. Materials Letters 79, 4-6 (2012). DOI: $10.1016 /$ j.matlet.2012.03.070

[12] Slepička P., Michaljaničová I., Švorčík V.: Controlled biopolymer roughness induced by plasma and excimer laser treatment. Express Polymers Letters, 7, 950-959 (2013).

DOI: $10.3144 /$ expresspolymlett.2013.92 
[13] Malmsten M.: Biopolymers at interfaces. Mercel Dekker, New York (2003).

[14] Brostow W., Hagg Lobland H. E., Narkis M.: Sliding wear, viscoelasticity, and brittleness of polymers. Journal of Materials Research, 21, 2422-2428 (2006). DOI: $10.1557 /$ jmr.2006.0300

[15] Pfleging W., Torge M., Bruns M., Trouillet V., Welle A., Wilson S.: Laser- and UV-assisted modification of polystyrene surfaces for control of protein adsorption and cell adhesion. Applied Surface Science, 255, 5453 5757 (2009).

DOI: $10.1016 /$ j.apsusc. 2008.08.053

[16] Brostow W., Cassidy P. E., Macossay J., Pietkiewicz D., Venumbaka S.: Connection of surface tension with multiple tribological properties in epoxy + fluoropolymer systems. Polymer International, 52, 1498-1505 (2003).

DOI: $10.1002 /$ pi.1283

[17] Bäuerle D., Denk R., Pedarning J. D., Piglmayer K., Heitz J., Schrems G.: Perspectives of laser processing and chemistry. Applied Physics A, 77, 203-207 (2003). DOI: 10.1007/s00339-003-2155-Z

[18] Rytlewski P., Zenkiewicz M.: Laser modification of polymeric materials. Part 2. Chemical reactions induced by laser beam. International Polymer Science and Technology, 34, T/59-T/66 (2007).

[19] Oehr C.: Plasma surface modification of polymers for biomedical use. Nuclear Instruments and Methods in Physics Research Section B: Beam Interactions with Materials and Atoms, 208, 40-47 (2003).

DOI: $10.1016 / \mathrm{S} 0168-583 X(03) 00650-5$

[20] Wochnowski C., Shams Eldin M. A., Metev S.: UVlaser-assisted degradation of poly(methyl methacrylate). Polymer Degradation and Stability, 89, 252-264 (2005).

DOI: $10.1016 /$ j.polymdegradstab.2004.11.024

[21] Rebollar E., Frischauf I., Olbrich M., Peterbauer T., Hering S., Preiner J., Hinterdorfer P., Romanin C., Heitz J.: Proliferation of aligned mammalian cells on laser-nanostructured polystyrene. Biomaterials, 29, 1796-1806 (2008).

DOI: $10.1016 /$ j.biomaterials.2007.12.039
[22] Mirzadeh H., Bagheri Sh.: Comparison of the effect of excimer laser irradiation and RF plasma treatment on polystyrene surface. Radiation Physics and Chemistry, 76, 1435-1440 (2007). DOI: 10.1016/j.radphyschem.2007.02.079

[23] Slepička P., Rebollar E., Heitz J., Švorčík V.: Gold coatings on polyethyleneterephthalate nano-patterned by F2 laser irradiation. Applied Surface Science, 254, 3585-3590 (2008).

DOI: $10.1016 /$ j.apsusc. 2007.11.045

[24] Slepička P., Chaloupka A., Sajdl P., Heitz J., Hnatowicz V., Švorčík V.: Angle dependent laser nanopatterning of poly(ethylene terephthalate) surfaces. Applied Surface Science, 257, 6021-6025 (2011).

DOI: 10.1016/j.apsusc.2011.01.107

[25] Lazare S., Bolle M., Cros A., Bellard L.: Periodic structuration of polymer surfaces with the excimer laser radiation. Nuclear Instruments and Methods in Physics Research Section B: Beam Interactions with Materials and Atoms, 105, 159-163 (1995). DOI: 10.1016/0168-583X(95)00630-3

[26] Rytlewski P., Żenkiewicz M.: Laser-induced surface modification of polystyrene. Applied Surface Science, 256, 857-861 (2009).

DOI: 10.1016/j.apsusc.2009.08.075

[27] Pfleging W., Bruns M., Welle A., Wilson S.: Laserassisted modification of polystyrene surfaces for cell culture applications. Applied Surface Science, 253, 9177-9184 (2007).

DOI: 10.1016/j.apsusc.2007.05.047

[28] Slepička P., Michaljaničová I., Sajdl P., Fitl P., Švorčík V.: Surface ablation of PLLA induced by KrF excimer laser. Applied Surface Science, 283, 438-444 (2013). DOI: $10.1016 /$ j.apsusc.2013.06.127

[29] Siegel J., Slepička P., Heitz J., Kolská Z., Sajdl P., Švorčík V.: Gold nano-wires and nano-layers at laserinduced nano-ripples on PET. Applied Surface Science, 256, 2205-2209 (2010). DOI: $10.1016 /$ j.apsusc. 2009.09.074

[30] Slepička P., Neděla O., Sajdl P., Kolská Z., Švorčík V.: Polyethylene naphthalate as an excellent candidate for ripple nanopatterning. Applied Surface Science, 285, 885-892 (2013).

DOI: $10.1016 / \mathrm{j}$. apsusc.2013.09.007 